\title{
HUBUNGAN PERAN EDUCATOR PERAWAT DALAM DISCHARE PLANNING DENGAN TINGKAT KEPATUHAN PASIEN RAWAT INAP UNTUK KONTROL DI RUMAH SAKIT GRANDMED LUBUK PAKAM
}

\section{PITRIANI ${ }^{1}$, SAMUEL GINTING ${ }^{2}$, DIAN ANGGRI YANTI ${ }^{3}$, JUNI MARIATI SIMARMATA ${ }^{4}$, ARFAH MAY SYARA ${ }^{5}$, RITA AYU BUTAR-BUTAR ${ }^{6}$}

\author{
1,2,3,4,5,6 Fakultas Keperawatan Dan Fisioterapi \\ Institut Kesehatan Medistra Lubuk Pakam \\ Jl. Sudirman No. 38 Lubuk Pakam Kab. Deli Serdang, \\ Sumatera Utara \\ e-mail: anipitri663@gmail.com \\ DOI $10.35451 /$ jkf.v3i2.603
}

\begin{abstract}
The role of educators is to help patients improve their health by providing knowledge about medical treatments and actions received so that patients or families can find out important knowledge for patients or their families. The research objective was to analyze the relationship between the role of the nurse educator in discharge planning with the level of compliance of in patients for control at Grandmed Lubuk Pakam Hospital. The research method is this research using analytic observational research using a cross sectional study. In a study with a cross sectional study, measurement and data collection were carried out on the cause and effect variables for a moment at a time. The results of the research in this study The statistical test results showed the value of $p=0.001$. Ha is accepted if Ho is rejected, where Ho is rejected if the $p$ value is $\leq a, 0.001 \leq 0.05$. The results of statistical analysis showed that there was a significant relationship between the role of nurse educators in discharge planning and the level of inpatient compliance for control. And Conclusion for this research: The role of nurse educators in discharge planning was in the good category, namely 23 people, the level of patient adherence to control was 24 people (60\%). For further researchers: Conducting further research on other factors that can affect patient adherence to control. Conducting further research using observation techniques, namely researchers participate directly in the activities carried out by nurses in carrying out the educator role in discharge planning.
\end{abstract}

Keywords: the role of educator, compliance, discharge planning.

\section{PENDAHULUAN}

Unsur penting yang terlibat dalam memberikan pelayanan kesehatan kepada pasien tidak hanya fokus pada kecukupan sarana prasarana yang dapat dijadikan cerminan kualitas pelayanan, tetapi tentang pemenuhan hak pasien sejak awal Masuk pasien sampai akhirnya membuat pasien keluar dari rumah sakit Salah satu hak yang melekat pada pasien dan keluarganya saat dirawat di rumah 
sakit untuk berobat adalah mendapatkan informasi yang lengkap tentang kesehatannya dalam hal perencanaan pulang. (Asmuji, et all. 2018).

Discharge planning merupakan transisi perawatan pasien dari pengaturan rumah sakit ke rumah, penyedia perawatan primer atau masyarakat dan perencanaan pulang yang efektif sangat penting dalam meningkatkan waktu pemulihan pasien karena merupakan bagian integral dari perawatan pasien. Impementasi perencanaan pulang yang buruk dikaitkan dengan berbagai konsekuensi baik untuk pasien / keluarga individu dan sistem kesehatan secara keseluruhan. (Baker, et all, 2019).

Manajemen pada perencanaan pulang dimulai dari penerimaan pasien, review intervensi, implementasi dan evaluasi. Pelaksanaan perencanaan pulang memberikan penyuluhan kese hatan untuk menambah pengetahuan dan dukungan keluarga saat pasien menjalani pengobatan di rumah. Perawat, dokter, ahli gizi, apoteker dan terapis adalah tim kesehatan untuk dilakukan perencanaan pulang. (Gholizadeh, 2016).

$$
\text { Program discharge planning }
$$

yang difokuskan pada pemberian penyuluhan kesehatan kepada pasien meliputi gizi, kegiatan atau pelatihan ,obat-obatan dan petunjuk khusus tentang tanda dan gejala penyakit yang diderita pasien. Sebelumpasien akan dipulangkan, pasien dan keluarganya perlu menge tahui bagaimana mengelola kondisi dan / atau pemulihannya. Mengajar pasien dan keluarganya adalah tugas perawat sebagai bagian dari strategi inovatif yang berada di garis depan perawatan pasien (Asmuji, 2018).
Perawat dituntut mampu untuk dapat memberikan pelayanan yang profesional dengan mengerahkan kemampuan serta keterampilan terbaiknya untuk membantu dalam proses dari kesembuhan klien. Salah satu cara yang akan dapat dilakukan perawat dalam membantu klien untuk kesembuhan pasien yaitu dengan mempersiapkan klien untuk menyusun discharge planning. (Rezkiki. Fardillah (2019).

Perencanaan pulang tidak han ya meningkatkan kualitas hidup pasien tetapi juga keluarga mereka. Selain itu, perencanaan pulang meningkatkan keselamatan pasien. Oleh karena itu, perencanaan pulang sangat penting dalam sistem kesehatan dan kurangnya perencanaan pulang yang efektif merupakan tantangan utama dalam meningkatkan kualitas peraw atan. (Gholizadeh, et all, 2016).

Masalah kesehatan yang pada umumnya dialami pasien adalah ketidaktahuan akan gejala penyakit, dan keterlambatan meminta pertolongan dari pelayanan kesehatan. Hal ini dapat disebabkan oleh kurangnya kesadaran dan perilaku. Kondisi ini dapat dialami oleh pasien setelah menjalani rawat inap, terutama akibat pelaksanaan perenca naan pulang yang tidak efektif di rumah sakit. Permasalahan utamanya adalah masih banyaknya kejadian perencanaan pulang di rumah sakit dalam kategori cukup $(83,24 \%)$

(Saputra et all, 2020).

Hasil wawancara ketika peneliti melaksanakan studi pendahuluan tentang suatu tindakan kepatuhan pasien untuk kontrol menunjukkan bahwa tidak semua pasien melaksanakan kontrol di Poli Rumah Sakit Grandmed Lubuk Pakam, setelah pulang dari rawat inap di rumah sakit, dikarenakan pasien 
menganggap terlalu jauh untuk dapat pergi kontrol di Rumah Sakit Grandmed Lubuk Pakam, keterbatasan biaya untuk kontrol, dan adanya pasien yang di anjurkan kontrol dipuskesmas atau menginginkan kontrol ditempat praktik dokter. Data rekam medis 50 pasien rawat inap pada bulan Maret 2020 menunjukkan sebanyak 15 pasien (35\%) tidak patuh untuk kontrol dan 35 pasien $(65 \%)$ patuh untuk kontrol.

Waktu kunjungan untuk kontrol di Poli Rumah Sakit Grandmed Lubuk Pakam antara 3 hari sampai 7 hari setelah pasien keluar dari menjalank an rawat inap. Tidak semua pasien melakukan kunjungan kembali untuk melaksanakan kontrol sesuai anjuran dari perawat. Hal ini membuat peneliti tertarik untuk melakukan penelititan dengan judul "hubungan peran educator perawat dalam discharge $\mathrm{pl}$ anning dengan tingkat kepatuhan pasien rawat inap untuk kontrol di ru mah sakit grandmed lubuk pakam tahun 2021".

\section{METODE}

Penelitian ini menggunakan je nis penelitian observasional analitik dengan menggunakan studi cross sectional yaitu dilakukan pengukuran dan pengumpulan data pada variabel sebab dan akibatnya sesaat dalam satu waktu. Pada penelitian ini, peneliti mencoba mencari hubungan

Antara variabel independent yaitu peran educator perawat dalam discharge planning dengan variabel dependent yaitu seperti adanya tingkat kepatuhan pasien untuk kont rol yang kemudian dilakukan analisis terhadap data yang terkumpul dan seberapa besar hubungan antar variabelnya.

\section{HASIL}

Berdasarkan penelitian yang telah dilakukan kepada 30 orang pasien yang menjadi responden diruang rawat inap $4 \mathrm{~T}$ (Tengah) Rumah Sakit Grandmed Lubuk

Pakam yang telah memenuhi syarat menjadi responden dengan ketentuan yang telah dibuat. Kriteria inklusi dari penelitian ini adalah pasien dalam keadaan sadar, pasien yang dianjurkan kontrol, Pasien ruang rawat inap 4T Rumah Sakit Grandmed Lubuk Paka $\mathrm{m}$. pasien yang bersedia menjadi responden. Kriteria ekslusi dari penelitian ini adalah pasien yang meninggal sebelum diberikan discharge planning.

3.1 Peran educator perawat dalam
discharge planning.
Tabel 1. Peran educator perawat
dalam discharge planning

Lebih dari 50 persen responden mempersepsikan peran educator pera wat dalam discharge planning denga $\mathrm{n}$ kategori baik sebanyak 23 orang $(57.5 \%)$. 
3.1 Tingkat kepatuhan pasien rawat inap untuk kontrol di Rumah Sakit Grandmed Lubuk Pakam.

Tabel 2. Tingkat kepatuhan pasien rawat inap untuk kontrol di Rumah Sakit Grandmed Lubuk Pakam

\begin{tabular}{llll}
\hline No & $\begin{array}{l}\text { Tingkat } \\
\text { kepatuhan } \\
\text { pasien } \\
\text { rawat } \\
\text { ianap }\end{array}$ & Jumlah & Persentase \\
\hline 1. Patuh & 24 & $60 \%$ \\
\hline 2. Tidak Patuh & 16 & $40 \%$ \\
\hline Jumlah & 40 & $100 \%$ \\
\hline
\end{tabular}

Tabel 2 menunjukkan dari 40 pasien yang dianjurkan untuk kontrol di instalasi rawat jalan Rumah Sakit Grandmed Lubuk Paka $\mathrm{m}$, diketahui bahwa lebih dari 50 persen yaitu 24 orang (60\%) patuh untuk kontrol.

\subsection{Hubungan peran educator} perawat dalam discharge planning dengan tingkat kepatuhan pasien rawat inap untuk kontrol di Rumah Sa kit Grandmed Lubuk Pakam.

Peran educator perawat dalam discharge planning yang dipersepsika $\mathrm{n}$ oleh 23 responden dalam kategori baik sebagian besar patuh untuk mel aksanakan kontrol sebanyak 19 orang $(82,6 \%)$, sisanya 4 orang $(17,4 \%)$ tidak patuh untuk kontrol.

Tabel 3. Hubungan peran educator perawat dalam discharge planning dengan tingkat kepatuhan pasien rawat inap untuk kontrol di Rumah

Sakit Grandmed Lubuk Pakam

\begin{tabular}{|ccccccc|}
\hline Baik & 12 & 70 & 5 & 29 & 10 & 0 \\
& & 6 & & .4 & 0 & 00 \\
\hline Tidak & 4 & 17, & 19 & 82 & 10 & 1 \\
baik & & 4 & & .6 & 0 & \\
\hline Total & 16 & 40 & 24 & 60 & $\begin{array}{c}10 \\
0\end{array}$ & \\
\hline
\end{tabular}

Tabel 3 Menunjukkan hubungan peran educator perawat dalam discharge planning dengan tingkat kepatuhan pasien rawat inap untuk kontrol di Rumah Sakit Grandmed Lubuk Pakam, diperoleh data dari 17 responden yang mempersepsikan peran educator perawat dalam discharge planning dengan kategori tidak baik menunjukkan lebih dari 50 persen responden mempunyai tingkat kepatuhan pasien untuk kontrol dalam kategori tidak patuh yaitu sebanyak 12 orang $(70,6 \%)$.

Hasil uji statistik menunjukkan

nilai $p=0.001$. Ha diterima jika, jika nilai $p \leq a, 0,001 \leq 0,05$. Hasil analisis statistik didapatkan bahwa ada hubungan signifikan antara peran educator perawat dalam discharge planning dengan tingkat kepatuhan pasien rawat inap untuk kontrol di rumah Sakit Grandmed Lubuk Pakam.

\section{PEMBAHASAN}

\subsection{Peran Educator Perawat dalam Discharge Planning}

Tabel 3 menunjukkan bahwa lebih dari 50 persen pelaksanaan per an educator perawat dalam discharg planning dipersepsikan dengan kateg ori baik yaitu 23 orang (57.5\%), sisanya 17 orang $(42.5 \%)$ dan mempersepsikan peran educator pera

\begin{tabular}{|c|c|c|c|c|c|c|}
\hline \multirow{3}{*}{$\begin{array}{l}\text { Peran } \\
\text { educator } \\
\text { Per } \\
\text { aw } \\
\text { at }\end{array}$} & \multicolumn{4}{|c|}{$\begin{array}{c}\text { Tingkat kepatuhan } \\
\text { untuk kontrol }\end{array}$} & \multirow{3}{*}{$\begin{array}{c}\text { to } \\
\text { ta } \\
\text { I }\end{array}$} & \multirow{3}{*}{$\begin{array}{l}\text { Vwat dalam discharge planning denga } \\
\text { vđi kategori tidak baik. Perawat dalam } \\
\text { lumenjalankan peran educator memba } \\
\text { entu pasien untuk meningkatkan kese }\end{array}$} \\
\hline & $\begin{array}{l}\text { Tidak } \\
\text { patuh }\end{array}$ & & & & & \\
\hline & $\mathrm{F}$ & $\%$ & $F$ & $\%$ & & \\
\hline
\end{tabular}


huan terkait dengan keperawatan dan tindakan medis yang diterima sehing ga pasien atau keluarga dapat mene rima tanggung jawab terhadap halhal yang diketahuinyaa(Rezkiki,Fardill ah, 2019).

Discharge planning memainkan peranan yang lebih penting untuk memastikan kesinambungan perawat an di semua lingkungan. Perawat yang belum menyampaikan discharge planning seluruh komponen pengetahuan secara jelas dan lengkap dapat menyebabkan meningkatnya angka kekambuhan pasien setelah berada di dalam rumah, dikarenakan pasien dan kelu arga belum mampu untuk melakukan perawatan secara mandiri (Sulistyawati, et all. 2016).

Menurut asumsi peneliti bahwa per an dari educator untuk memberikan Informasi tentang discharge planning memang harus di lakukan agar nanti nya pasien yang akan kembali kerumah dapat mengetahui informasi apa saja yang akan dibawanya saat kembali kerumah untuk kesehatannya.

\subsection{Tingkat Kepatuhan Pasien Rawat Inap untuk Kontrol.}

Kepatuhan secara umum didefini sikan sebagai tingkatan perilaku sese orang yang mendapatkan pengobatan, mengikuti prosedur di rumah sakit, dan melaksanakan gaya hidup sesuai dengan rekomendasi pemberi pelayanan kesehatan. Pasien akan patuh menjalankan sesuai dengan yang diperintahkan kepadanya apabila Pasien paham terhadap instruksi yang diperintahkan Pasien yang tidak paham terhadap instruksi yang diberikan kepadanya maka tidak dapat mematuhi instruksi tersebut dengan baik (Ilmah, 2015).

Tingkat kepatuhan pasien untuk kontrol dilihat dari data rekam medis responden yang sudah ditentukan oleh peneliti sebanyak 40 responden, diketahui bahwa lebih dari 50 persen yaitu 24 orang $(60 \%)$ patuh untuk kontrol, sisanya 16 orang (40\%) tidak patuh untuk kontrol.

\subsection{Hubungan Peran Educator Perawat dalam Discharge Planning dengan Tingkat Kepatuhan Pasien Rawat Inap untuk Kontrol.}

Data dari 17 responden yang mempersepsikan peran educator perawat dalam discharge planning dengan kategori tidak baik menunjukkan lebih dari 50 persen responden mempunyai tingkat kepatuhan dari pasien untuk dapat kontrol dalam kategori tidak patuh yaitu sebanyak 12orang $(70,6 \%)$, sisanya 5 orang $(29,4 \%)$ patuh untuk kontrol.

Peran educator perawat dalam di scharge planning yang dipersepsikan oleh 23 responden dalam kategori baik sebagian besar patuh untuk me laksanakan kontrol yaitu sebanyak 19 orang $(82,6 \%)$, sisanya 4 orang $(17,4 \%)$ tidak patuh untuk kontrol.

Hasil uji statistik menunjukkan

nilai $p=0.001$. Ha diterima jika Ho ditolak, dimana Ho ditolak jika nilai $p \leq a, 0,001 \leq 0,05$. Hasil analisis statistik didapatkan bahwa ada hubu ngan signifikan antara peran educat or perawat dalam discharge planning dengan tingkat kepatuhan pasien rawat inap untuk kontrol di Rumah Sakit Grandmed Lubuk Pakam.

Menurut asumsi dari peneliti Komunikasi antara perawat dan pasie $\mathrm{n} /$ keluarga dalam pendidikan keseha tan sangat penting dalam perencanaan pemulangan yang akan memudahkan pasien dalam menerima atau mema hami instruksi yang diberikan untuk pasien ketika berada di rumah yang 
dapat secara mandiri menjaga atau meningkatkan kesehatannya .Komuni kasi yang efektif juga akan meningkatkan kapatuhan pasien unt uk kontrol. Kontrol dilakukan untuk mengevaluasi kesehatan pasien karena pasien tidak dapat malaksanakan secara madiri tanpa bantuan petugas kesehatan.

\section{KESIMPULAN}

Peran educator perawat dalam discharge planning lebih dari 50 persen dipersepsikan dengan kategori baik yaitu sebanyak 23 orang $(57.5 \%)$, sisanya 17 orang $(42.5 \%)$ mempersepsikan peran educator perawat dalam discharge planning dengan kategori tidak baik. Tingkat kepatuhan pasien untuk kontrol diketahui lebih dari 50 persen pasien patuh untuk kontrol yaitu sebanyak 24 orang $(60 \%)$, sisanya 16 orang $(40 \%)$ tidak patuh untuk kontrol.

Ada hubungan yang signifikan antara peran educator perawat dalam discharge planning dengan tingkat kepatuhan pasien rawat inap untuk kontrol di Rumah Sakit Grandmed Lub uk Pakam.

\section{DAFTAR PUSTAKA}

Asmuji, et all (2018). FAKTOR FAKTOR YANG BERHUBUNGAN DENGAN KAPASISTAS KERJA TERHADAP PERILAKU CARING PERAWAT DI RSD BALUNG.

DOI: https://doi.org/10.32528/psn.v0i 0.1754 .

Baker, et all (2019). KEPUASAN PASIEN DALAM PELAKSANAAN DISCHARGE PLANNING. http://ejournal.unair.ac.id/FMNJ.

Gholizadeh, M., Delgoshaei, B., Gorji, H. A., Torani, S., \& Janati, A. (2016). CHALLENGES IN PATIENT DISCHARGE
PLANNING IN THE HEALTH SYSTEM OF IRAN: A QUALITATIVE STUDY. Global journal of health science, 8(6), 168.

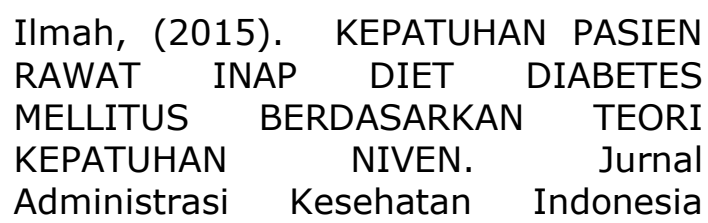
Volume 3 Nomor 1 Januari-Juni 2015.

Rezkiki. Fardillah (2019). DESKRIPSI PELAKSANAAN DISCHARGE PLANNING DI RUANG RAWAT INAP. REAL in Nursing Journal (RNJ), Vol. 2, No. 3 Rezkiki, F \& Fardilah, VN. (2019). RNJ. 2(3) : 126-136.

Saputra, et, all (2020). HUBUNGAN PENGETAHUAN PERAWAT TENTANG DISCHARGE PLANNING DENGAN PELAKSANAAN DISCHARGE PLANNING : Literature Review.

Sulistyawati, W., Hariyati, R. and Kuntarti (2016) 'IMPLEMENTASI SISTEM JENJANG KARIR DALAM PELAKSANAAN DISCHARGE PLANNING', Jurnal IImu Keperawatan, 4. Medika. 